\title{
Prevention of Amyloidosis in Familial Mediterranean Fever with Colchicine: A Case-Control Study in Armenia
}

\author{
Maria K. Sevoyan ${ }^{a}$ Tamara F. Sarkisian $^{b}$ Ara A. Beglaryan ${ }^{b}$ \\ Gohar R. Shahsuvaryan ${ }^{b}$ Haroutune K. Armenian ${ }^{c}$ \\ ${ }^{a}$ American University of Armenia and ${ }^{b}$ Center of Medical Genetics and Primary Health Care, Yerevan, Armenia; \\ 'Department of Epidemiology, Johns Hopkins University School of Public Health, Baltimore, Md., USA
}

\section{Key Words}

Familial Mediterranean fever, case-control study •

Amyloidosis $\cdot$ Colchicine

\begin{abstract}
Objective: To determine whether or not the use of colchicine decreases the risk of amyloidosis among Armenian patients with familial Mediterranean fever (FMF). Subjects and Methods: The study included 99 Armenian patients from the Center of Medical Genetics database with genetically ascertained FMF; 33 had renal amyloidosis and 66 were randomly selected control patients without renal amyloidosis. Selfreported colchicine use was assessed by interviewer-based questionnaire. Results: The patients with incident amyloidosis were more likely to be older men, but younger at the time of disease onset, and more likely to have had a family history of amyloidosis and M694F mutation in the MEFV gene compared to patients without amyloidosis. The risk of amyloidosis decreased with adequate colchicine use rather than nonadequate use (adjusted odds ratio, OR, 0.48, 95\% confidence interval, $\mathrm{Cl}, 0.16-1.43)$, continuous colchicine use rather than interrupted use (adjusted OR $0.15,95 \% \mathrm{Cl} 0.04-$ 0.53), earlier rather than later initiation age of colchicine treatment (adjusted OR 0.95, 95\% Cl 0.90-1.01), current colchicine rather than ever/never colchicine use (adjusted OR $0.20,95 \% \mathrm{Cl} 0.05-0.89)$. Conclusion: The study demonstrat-
\end{abstract}

ed that colchicine treatment is effective in preventing amyloidosis among Armenian patients with FMF and that earlier initiation and continuous therapy at an adequate dose of 1.2-1.8 mg/day may be associated with a decreased amyloidosis risk among Armenian patients with FMF.

Copyright $\odot 2009$ S. Karger AG, Basel

\section{Introduction}

Familial Mediterranean fever (FMF), also known as familial paroxysmal polyserositis, is an inherited autoinflammatory disorder characterized by recurrent and selflimiting episodes of fever and serositis. The disease is characterized by severe and painful attacks of peritonitis, pleuritis and arthritis [1,2] and is most common among people of Mediterranean origin [1]. Renal amyloidosis causing chronic renal failure is a frequent occurrence among patients with FMF [1-3]. The prevalence of amyloidosis varies in different case series: $0 \%$ in California [4], 6\% in Lebanon [5], 27\% in Israel and 24\% in Armenia $[1,5-7]$.

Daily prophylactic treatment of FMF with colchicine was suggested by Goldfinger [8] and assessed by doubleblind randomized studies [9-11]. It was reported that continuous use of 1.0-2.0 mg/day of colchicine diminished the frequency and severity of attacks and could prevent

\section{KARGER}

Fax +4161306 1234

E-Mail karger@karger.ch

www.karger.com
(C) 2009 S. Karger AG, Basel

1011-7571/09/0186-0441\$26.00/0

Accessible online at:

www.karger.com/mpp
Maria K. Sevoyan

7 Hovsep Emin Street, Apt. 10

AM-0033 Yerevan (Republic of Armenia)

Tel. +374 10226690

E-Mail maria_sevoyan@yahoo.co.uk 
amyloidosis developing in patients with FMF [12-15]. In most studies, evidence for reduction of attack frequency and prevention of amyloidosis by colchicine therapy was demonstrated in both experimental trials [9-11] and clinical observations $[14,16]$. To adequately demonstrate the effectiveness of colchicine therapy for the prevention of amyloidosis, a case-control study is needed [17]. The casecontrol method gives an opportunity to study multiple exposures at the same time (different duration, different schemes and different colchicine dosing).

The objective of this study was to use the case-control method to determine whether or not the use of colchicine decreases the risk of amyloidosis among Armenian patients with FMF, as it has been shown that the incidence of FMF and FMF-associated amyloidosis remains high in Armenia [18].

\section{Subjects and Methods}

\section{Ethical Considerations}

The study was approved by the Institutional Review Board/ Committee on Human Research of the American University of Armenia. Permission was received for the study from the head of the Center of Medical Genetics (CMG). Oral informed consent was obtained from the patients after adequate explanation had been given for the purpose, methods and anticipated benefits of the study.

\section{Study Setting and Participants}

A case-control study was designed with two controls per case. The source population consisted of Armenian patients with genetically ascertained FMF in the period between 2000 and 2005 living in Yerevan and registered for follow-up in the CMG. Patients with FMF from regions of Armenia (other administrativeterritorial parts of Armenia, except Yerevan), non-Armenian residents of Yerevan, patients with incomplete medical records and without contact information were excluded from the study. Our cases were defined as incident cases of renal amyloidosis developed during the period from August 2003 to August 2005. Our controls were FMF patients without renal amyloidosis by the end of the observation period.

Verification of the FMF diagnosis by genetic test in Armenia is available only in the CMG. Seven MEFV (M694V, V726A, M680I, F479L, E148Q, M694I, R761H) mutations were systematically investigated among the patients. During molecular testing, genomic DNA was extracted from peripheral blood using a Puregene kit (Gentra System, USA) according to standard procedures. DNA was amplified by the PCR technique with specific primers for the $M E F V$ gene region, and the screening of $M E F V$ gene mutations was accomplished by mutation-specific restriction endonuclease analyses for $7 M E F V$ mutations from exons 2, 3, 5 and 10 [18].

Study participants were selected from the database of medical records available in the CMG. Patients with FMF included in the register are usually followed up by the family physicians and rheumatologists at the CMG. Patients with suspected FMF are referred to the CMG from other health care facilities for confirmation of the diagnosis by genetic analysis. Patients willing to be followed up by the CMG's physicians are registered in the center for regular examination and medical observation. Medical records of the FMF patients contain a patient's contact information, results of genetic testing and laboratory analyses and information regarding the treatment. Participants were selected after review of all medical records available at the CMG. Based on the exclusion and inclusion criteria, a total of 198 patients with FMF were identified from the database of the CMG. Of these, 42 patients with amyloidosis that developed during the period from August 2003 to August 2005 were included in the study as potential cases. Of the 42 patients with FMF-associated amyloidosis, 33 agreed to participate and were interviewed, 2 declined to participate and 7 could not be contacted. From the remaining 156 patients, those without amyloidosis were randomly selected as potential controls to ensure two controls per case. Of the 70 patients without amyloidosis, 66 were interviewed and 4 declined.

The CMG was the best source for selecting participants for the study, since the patients were accurately followed up and the first stage of amyloidosis could be detected. In general, the diagnosis of amyloidosis is confirmed by renal, rectal or gingival biopsy. In our study amyloidosis was diagnosed by either renal or rectal biopsy in 5 FMF patients and by persistent proteinuria in the remaining cases. Since biopsy is rarely performed in Armenia, we selected the remaining amyloidosis cases by the presence of proteinuria in at least two consecutive urine analyses and with normal levels of white blood cells in the urine (detection threshold $\geq 300 \mathrm{mg} / \mathrm{l})$ [19].

\section{Data Collection and Exposure Definition}

Patients were asked to come to the CMG in order to perform a face-to-face interview. In August 2005, an interviewer-administered questionnaire was used for collecting data regarding colchicine exposure among the cases and controls. The questionnaire consisted of the patients' demographic characteristics (sex, age, information about relatives suffering from FMF and/or renal amyloidosis), disease history (onset of the attacks, duration, frequency and clinical form of the attacks, involvement of joints, specific mutations of the $M E F V$ gene) and therapy (treatment initiation age, colchicine dose, duration of administration and skipping patterns). Renal amyloidosis was selected as the outcome variable. There were four colchicine exposure variables including: current colchicine use, colchicine use in adequate dose/duration, colchicine treatment initiation age and mode of colchicine use.

A patient was considered to be a current user of colchicine if he/she reported that he/she had been taking the pills within the month of the interview. The patient was considered to be an ever user if he/she had used colchicine but was not using it at the time of observation. The remaining patients were classified as having never used colchicine. Current users of colchicine were classified according to whether colchicine was used at an adequate dose/duration (1.2-1.8 mg/day for at least 1 year) or at an inadequate dose/ duration $(0.6-1.0 \mathrm{mg} /$ day or $1.2-1.8 \mathrm{mg}$ /day for less than 1 year). Finally, current colchicine users were classified by mode of colchicine use as continuous users or colchicine users with interruption. The index (reference) was considered to be the date of amyloidosis onset for cases and August 2004 (midpoint of August 2003 and August 2005) for controls. Potential confounders included sex, age, clinical characteristics of the disease and genetic factors. 
Table 1. Baseline characteristics of 66 FMF patients without amyloidosis and 33 FMF patients with amyloidosis developed from August 2003 to August 2005

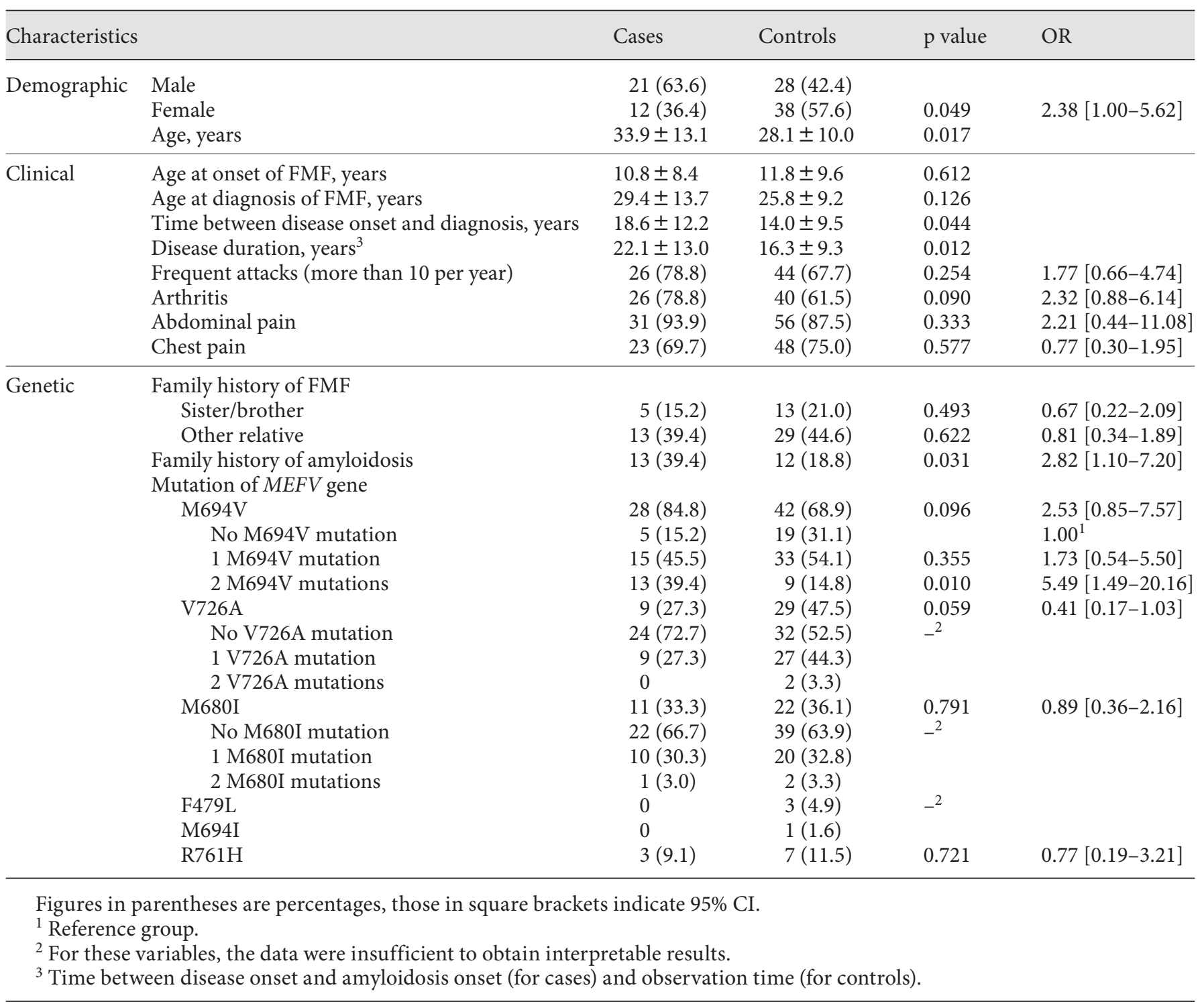

Statistical Analysis

All analyses were performed using Stata 7 statistical software. A two-sided $p$ value $<0.05$ was considered to be statistically significant. Differences between patients with and without amyloidosis were compared using $\chi^{2}$ analysis, calculation of odds ratios with $95 \%$ confidence intervals or t test, as appropriate. An unconditional multivariate logistic regression analysis was performed to control for confounding by age, gender, onset of disease, family history of amyloidosis or specific mutations of the $M E F V$ gene, as appropriate [20-23]. Potential confounders were selected on the basis of biologic plausibility or a strong univariate association. Besides the main effect models, the possibility of interaction terms was assessed among the variables.

Colchicine and Prevention of Amyloidosis

\section{Results}

\section{Study Sample Characteristics}

Data on 33 cases and 66 controls were collected. The refusal rate was $6 \%$ among cases and $6 \%$ among controls. Cases and controls differed significantly with respect to sex and age (table 1). In the case group, 21 (63.6\%) were males and $12(36.4 \%)$ females, while in the control group there were 28 (42.4\%) males and 38 (57.6\%) females. The average age of cases was higher than that of controls, 33.9 and 28.1 years, respectively.

Med Princ Pract 2009;18:441-446 
Table 2. Unadjusted comparisons of colchicine treatment of 33 cases and 66 controls

\begin{tabular}{|c|c|c|c|c|}
\hline Characteristics & Cases & Controls & $\mathrm{p}$ value & OR \\
\hline Current users & $26(78.8)$ & $59(89.4)$ & \multirow{3}{*}{0.161} & \multirow{3}{*}{$0.44[0.14-1.38]$} \\
\hline Ever/never users & $7(21.2)$ & $7(10.6)$ & & \\
\hline Adequate users & $13(48.2)$ & $44(73.3)$ & & \\
\hline Nonadequate users & $14(51.9)$ & $16(26.7)$ & 0.025 & $0.34[0.13-0.87]$ \\
\hline $\begin{array}{l}\text { Average age at initiation of } \\
\text { colchicine treatment, years }\end{array}$ & $32.0 \pm 13.0$ & $27.2 \pm 10.0$ & 0.065 & $1.04[0.99-1.08]$ \\
\hline \multicolumn{5}{|l|}{ Mode of colchicine use } \\
\hline Continuous & $12(44.4)$ & $45(75.0)$ & & \\
\hline With interruption & $15(55.6)$ & $15(25.0)$ & 0.007 & $0.27[0.10-0.70]$ \\
\hline \multicolumn{5}{|l|}{ Duration of interruption } \\
\hline Up to 3 months & 0 & $9(60.0)$ & -1 & \\
\hline From 3 to 6 months & $8(53.3)$ & $4(26.7)$ & & \\
\hline From 6 to 9 months & $4(26.7)$ & $1(6.7)$ & & \\
\hline From 9 to 12 months & $3(20.0)$ & $1(6.7)$ & & \\
\hline
\end{tabular}

Figures in parentheses are percentages, those in square brackets indicate 95\% CI. Adequate use: $1.2-1.8 \mathrm{mg} /$ day for at least 12 months.

${ }^{1}$ For these variables, the data were insufficient to obtain interpretable results.

Patients with amyloidosis were younger at the time of disease onset compared to those without amyloidosis. The average age at onset of FMF attacks in cases was 10.8 \pm 8.4 years, and for controls it was $11.8 \pm 9.6$ years. The period between disease onset and diagnosis time was longer in patients with amyloidosis than in other FMF patients, $18.6 \pm 12.2$ years and $14.0 \pm 9.5$ years. The average duration of the disease was also longer in cases (22.1 \pm 13.0 years $)$ than in controls $(16.3 \pm 9.3$ years; $p<0.05)$. Patients with amyloidosis were more likely to report a family history of amyloidosis (OR 2.82, 95\% CI 1.10-7.20) than those without amyloidosis. The presence of two M694V mutations in the MEFV gene versus no M694V mutation increased the risk of amyloidosis (OR 5.49, 95\% CI 1.49-20.16).

\section{Colchicine Treatment and Amyloidosis}

Of the 33 cases, 26 (78.8\%) - and of the 66 controls, 59 (89.4\%) - used colchicine at different doses and levels (0.6-1.8 mg/day) at the time of observation. Only $9.1 \%$ of controls mentioned that they had never used colchicine in contrast to $18.2 \%$ of cases (table 2). The risk of developing amyloidosis was lower in cases of adequate colchicine users than nonadequate users (OR 0.34, 95\% CI $0.13-$ 0.87). The average age of colchicine treatment initiation was $27.2 \pm 10.0$ years for controls compared with $32.0 \pm$ 13.0 years for cases. The risk of developing FMF-associ- ated amyloidosis decreased with earlier initiation of colchicine treatment. The risk of developing FMF-associated amyloidosis was lower in the case of continuous colchicine use than interrupted use (OR 0.27, 95\% CI $0.10-0.70)$.

The risk of developing amyloidosis among patients with FMF was lower among current colchicine users than noncurrent (ever/never) colchicine users controlling for age, gender, family history of amyloidosis and M694V mutation (adjusted OR 0.20, 95\% CI 0.05-0.89; table 3). Based on the multivariate logistic regression, the risk of developing FMF-associated amyloidosis was 52\% (10.48 ) lower in the case of adequate than nonadequate colchicine use after adjustment for potential confounders (adjusted OR 0.48, 95\% CI 0.16-1.43). Even after controlling for gender, onset of the FMF and genetic factors, the risk of developing FMF-associated amyloidosis was higher in the case of initiation of colchicine treatment at an older age versus earlier initiation of colchicine treatment. There was a protective effect of continuous versus interrupted use of colchicine for the risk of amyloidosis (adjusted OR 0.15, 95\% CI 0.04-0.53).

The interactions between adequate colchicine use and presence of specific $M E F V$ mutations or family history of amyloidosis were considered, but the number of observations was not sufficient to detect statistically significant interactions at the 0.05 level of significance. 
Table 3. Multivariate logistic regression models of colchicineincident amyloidosis association

\begin{tabular}{lll}
\hline $\begin{array}{l}\text { Exposure variables } \\
\text { OR }\end{array}$ & $\begin{array}{l}\text { Crude-model } \\
\text { ORlchicine use }\end{array}$ & $\begin{array}{l}\text { Adjusted-model } \\
\text { OR }\end{array}$ \\
$\begin{array}{l}\text { Current } \\
\quad \text { Ever/never }\end{array}$ & $0.44(0.14-1.38)$ & $0.20(0.05-0.89)^{1}$ \\
Adequate use of colchicine & 1.00 & 1.00 \\
$\quad \begin{array}{l}\text { Adequate users } \\
\quad \text { Nonadequate users }\end{array}$ & $0.34(0.13-0.87)$ & $0.48(0.16-1.43)^{1}$ \\
$\begin{array}{l}\text { Age at initiation of } \\
\quad \text { colchicine treatment }\end{array}$ & 1.00 & 1.00 \\
$\begin{array}{l}\text { Mode of colchicine use } \\
\quad \text { Continuous }\end{array}$ & $0.27(0.10-0.70)$ & $0.15(0.04-0.53)^{1}$ \\
$\quad$ With interruption & 1.00 & 1.00 \\
\hline
\end{tabular}

Figures in parentheses indicate 95\% CI. Adequate use: 1.2-1.8 $\mathrm{mg}$ /day for at least 12 months.

${ }^{1}$ Adjusted for age, gender, family history of amyloidosis and M694V.

${ }^{2}$ Adjusted for onset of FMF, gender, family history of amyloidosis and M694V.

\section{Discussion}

The natural history of FMF is characterized by long periods of febrile painful episodes and insidious development of renal amyloidosis, whether after several years of the attacks or as the first manifestation of the disease [1, 24]. The major manifestation of FMF amyloidosis is nephropathy, beginning with proteinuria and progressing to nephrotic syndrome and renal failure. In most cases of amyloidosis, renal failure develops after several years of progressive nephropathy, and then patients reach end stage renal disease when treatment by chronic dialysis and renal transplantation is required $[1,24]$.

This study was conducted to evaluate colchicine treatment effectiveness in preventing renal amyloidosis among Armenian patients with FMF. The main findings of our study were statistically significant associations (protective effect) between colchicine treatment and the risk of developing FMF-associated amyloidosis. An important result of the study was that the adequate and continuous uses of colchicine as well as earlier age at initiation of treatment were protective of amyloidosis development in patients with FMF and remained protective after adjusting for demographic characteristics and genetic factors. The findings of the current study regarding the effective-

Colchicine and Prevention of Amyloidosis ness of colchicine therapy were consistent with the results of previous reports $[14,16]$.

Previous research illustrated the effectiveness of colchicine by a two-thirds reduction in prevalence of amyloidosis in a cohort study with 7-11 years of follow-up among Jewish FMF patients [14]. Another cohort study with 4 years of follow-up showed an extremely low cumulative incidence $(0.4 \%)$ of proteinuria among patients treated with colchicine as compared to untreated patients (18.5\%) from other ethnic groups [16].

In vitro, colchicine has been shown to inhibit the secretion of serum amyloid A protein, the precursor of amyloid A protein [25]. If the pathogenesis of amyloidosis involved a simple overproduction of serum amyloid A leading to the amyloid fibril formation, then the effectiveness of colchicine could be easily explained. However, some studies showed that amyloidosis is genetically determined in patients with FMF $[22,26-30]$. The current study showed the strong association between a family history of amyloidosis and the risk of developing FMFassociated amyloidosis (OR 2.82, 95\% CI 1.10-7.20). Colchicine provides protection from developing amyloidosis not only in patients whose attacks were relieved by colchicine, but also in those whose attacks were not alleviated by the drug [14]. It seems that prevention of amyloidosis by colchicine cannot be fully explained by suppression of the attacks or secretion of the amyloid precursor. However, placebo-controlled trials and observational studies following the preliminary observations confirmed that colchicine had not only been effective in preventing the attacks, but also in preventing secondary amyloidosis $[14,16]$.

Our study had several strengths. It was the first casecontrol study in Armenia to show the effectiveness of colchicine treatment in preventing amyloidosis associated with FMF. It provided availability to detailed information on genotypes (MEFV gene mutations) for the FMF patients and thus the ability to adjust for them. It also provided an opportunity to measure the effectiveness of colchicine in the prevention of amyloidosis development under real-life conditions.

However, the study had some limitations as well. One was the small sample size which limited interpretation of the results of logistic regression for some variables. One recommendation would be to increase the sample size for future studies by recruiting FMF patients from other health care facilities and administrative-territorial parts of Armenia. Another potential problem could be misclassification bias by disease status. Proteinuria (in at least two subsequent urine analyses with normal levels of 
white blood cells in urine) was considered to indicate amyloidosis, but the assumption could possibly lead to overdiagnosis, thereby affecting the effectiveness of colchine therapy for the prevention of renal amyloidosis.

\section{Conclusion}

The study showed that colchicine treatment is effective in preventing amyloidosis among Armenian patients with FMF. It also showed that earlier initiation and con- tinuous therapy at an adequate dose of $1.2-1.8 \mathrm{mg} / \mathrm{day}$ seemed to be associated with a decreased risk of amyloidosis among Armenian patients with FMF.

\section{Acknowledgement}

The authors gratefully acknowledge and thank Gayane Yenokyan and Varduhi Petrosyan for their valuable comments and suggestions as well as all study participants.

\section{References}

1 Sohar E, Gafni J, Pras M, Heller H: Familial Mediterranean fever: a survey of 470 cases and review of the literature. Am J Med 1967; 43:227-253.

-2 Meyerhoff J: Familial Mediterranean fever: report of a large family, review of the literature, and discussion of the frequency of amyloidosis. Medicine (Baltimore) 1980;59:6677.

3 Armenian HK, Sha'ar KH: Epidemiologic observations in familial paroxysmal polyserositis. Epidemiol Rev 1986;8:106-116.

4 Schwabe AD, Peters RS: Familial Mediterranean fever in Armenians: analysis of 100 cases. Medicine (Baltimore) 1974;53:453-462.

5 Armenian HK, Khachadurian AK: Familial paroxysmal polyserositis: clinical and laboratory findings in 120 cases. J Med Liban 1973;26:605-614

6 Armenian HK: Enrollment bias and variation in clinical manifestations: a review of consecutive cases of familial paroxysmal polyserositis. J Chronic Dis 1983;36:209212.

7 Pras M, Bronshpigel N, Zemer D, Gafni J: Variable incidence of amyloidosis in familial Mediterranean fever among different ethnic groups. Johns Hopkins Med J 1982;150:2226.

-8 Goldfinger SE: Colchicine for familial Mediterranean fever. N Engl J Med 1972;287: 1302.

9 Goldstein RC, Schwabe AD: Prophylactic colchicine therapy in familial Mediterranean fever: a controlled, double-blind study. Ann Intern Med 1974;81:792-794.

- 10 Zemer D, Revach M, Pras M, Modan B, Schor S, Sohar E, Gafni J: A controlled trial of colchicine in preventing attacks of familial Mediterranean fever. N Engl J Med 1974;291: 932-934.

-11 Dinarello CA, Wolff SM, Goldfinger SE Dale DC, Alling DW: Colchicine therapy for familial Mediterranean fever: a double-blind trial. N Engl J Med 1974;291:934-937.
12 Livneh A, Zemer D, Langevitz P, Laor A, Sohar E, Pras M: Colchicine treatment of AA amyloidosis of familial Mediterranean fever: an analysis of factors affecting outcome. Arthritis Rheum 1994;37:1804-1811.

13 Zemer D, Livneh A, Danon YL, Pras M, Sohar E: Long-term colchicine treatment in children with familial Mediterranean fever. Arthritis Rheum 1991;34:973-977.

14 Zemer D, Pras M, Sohar E, Modan M, Cabili S, Gafni J: Colchicine in the prevention and treatment of the amyloidosis of familial Mediterranean fever. N Engl J Med 1986;314: 1001-1005.

15 Kallinich T, Haffner D, Niehues T, Huss K, Lainka E, Neudorf U, Schaefer C, Stojanov S, Timmann C, Keitzer R, Ozdogan H, Ozen S: Colchicine use in children and adolescents with familial Mediterranean fever: literature review and consensus statement. Pediatrics 2007;119:e474-e483.

16 Cabili S, Zemer D, Pras M, Aviram A, Sohar E, Gafni J: The prevention of amyloidosis in familial Mediterranean fever with colchicine. Proc Eur Dial Transplant Assoc Eur Ren Assoc 1985;21:709-711.

17 Selby JV: Case-control evaluations of treatment and program efficacy. Epidemiol Rev 1994;16:90-101.

18 Sarkisian T, Ajrapetyan H, Shahsuvaryan G: Molecular study of FMF patients in Armenia. Curr Drug Targets Inflamm Allergy 2005;4:113-116.

19 Hricik DE, Sedor JR, Ganz MB: Nephrology Secrets. Philadelphia, Hanley \& Belfus, 1999.

20 Cefle A, Kamali S, Sayarlioglu M, Inanc M, Ocal L, Aral O, Konice M, Gul A: A comparison of clinical findings of familial Mediterranean fever patients with and without amyloidosis. Rheumatol Int 2005;25:442446.

21 Livneh A, Langevitz P, Shinar Y, Zaks N, Kastner DL, Pras M, Pras E: MEFV mutation analysis in patients suffering from amyloidosis of familial Mediterranean fever. Amyloid 1999;6:1-6.
22 Ben Chetrit E, Backenroth R: Amyloidosis induced, end stage renal disease in patients with familial Mediterranean fever is highly associated with point mutations in the $M E F V$ gene. Ann Rheum Dis 2001;60:146-149.

23 Shinar Y, Livneh A, Langevitz P, Zaks N, Aksentijevich I, Koziol DE, Kastner DL, Pras M, Pras E: Genotype-phenotype assessment of common genotypes among patients with familial Mediterranean fever. J Rheumatol 2000;27:1703-1707.

24 Ozen S: Renal amyloidosis in familial Mediterranean fever. Kidney Int 2004;65:11181127.

25 Tatsuta E, Sipe JD, Shirahama T, Skinner M, Cohen AS: Colchicine inhibition of serum amyloid protein SAA and SAP synthesis in primary mouse liver cell cultures. Arthritis Rheum 1984;27:349-352.

26 Saatci U, Ozen S, Ozdemir S, Bakkaloglu A, Besbas N, Topaloglu R, Arslan S: Familial Mediterranean fever in children: report of a large series and discussion of the risk and prognostic factors of amyloidosis. Eur J Pediatr 1997; 156:619-623.

-27 Bakkaloglu A, Duzova A, Ozen S, Balci B, Besbas N, Topaloglu R, Ozaltin F, Yilmaz E: Influence of serum amyloid A (SAA1) and $S A A 2$ gene polymorphisms on renal amyloidosis, and on SAA/C-reactive protein values in patients with familial Mediterranean fever in the Turkish population. J Rheumatol 2004;31:1139-1142.

-28 Gershoni-Baruch R, Brik R, Zacks N, Shinawi $M$, Lidar $M$, Livneh $A$ : The contribution of genotypes at the $M E F V$ and $S A A 1$ loci to amyloidosis and disease severity in patients with familial Mediterranean fever. Arthritis Rheum 2003;48:1149-1155.

29 Heller H, Sohar E, Gafni J, Heller J: Amyloidosis in familial Mediterranean fever: an independent genetically determined character. Arch Intern Med 1961;107:539-550.

30 Gafni J, Ravid M, Sohar E: The role of amyloidosis in familial Mediterranean fever: a population study. Isr J Med Sci 1968;4:995-999. 